\title{
PROVAS E ARGUMENTOS NO DISCURSO HISTÓRICO *
}

\author{
Maria Beatriz Nizza da Silva
}

\begin{abstract}
"Aucune preuve n'a la même force, aucune idée la même évidence, aucune image le même charme pour tous les esprits".
\end{abstract}

\section{Diderot}

Devo esclarecer que, antes de me familiarizar com as traduções brasileiras de obras anglo-saxônicas de filosofia da ciência, a palavra evidência em português só possuía para mim o significado que proveio talvez da tradição filosófica francesa dos séculos XVII e XVIII, ou seja, aquilo que se impõe ao espírito com tal força que não há necessidade de nenhuma prova. No Discours préliminaire à l'Encyclopédie, d'Alembert escrevia: 'L'évidence appartient proprement aux idées dont l'esprit aperçoit la liaison tout d'un coup"

Mas, mesmo em inglês, a palavra evidência aponta em duas direções semânticas, por um lado ela é a informação que estabelece um fato e neste caso melhor seria empregar o termo prova; e por outro lado, ela é o fundamento de uma crença e neste caso mais correto será empregar a palavra argumento. Assim sendo, prefiro nesta minha intervenção falar do papel das provas e dos argumentos no conhecimento histórico, deixando de lado um termo que realmente não faz parte do meu vocabulário.

Parece-me conveniente deixar desde já bem claro que tudo o que vou dizer se refere à escritura histórica e não à pesquisa histórica, ao produto escrito do trabalho do historiador e não aquela fase mais ou menos nebulosa, conforme os casos, que 0 antecede. $O$ pesquisador só se torna historiador no momento em que comunica aos seus pares aquilo que descobriu, as conclusões a que chegou, pre-

- Comunicação feita na mesa redonda sobre "O papel da evidência no conhecimento historiográfico", durante o IV Encontro de História e Filosofia da Ciência, de 9 a 11 de dezembro de 1981, na Unicamp, organizado pelo Centro de Lógica e Epistemologia daquela Universidade. 
tendendo ao mesmo tempo convencê-los de que as suas conclusões estão corretas.

Um outro ponto há ainda a esclarecer previamente: quando falo de escritura histórica estou pensando naquela forma de discurso histórico elaborada para circular dentro da comunidade científica e não naquela outra destinada ao leigo ou então redigida para fins didáticos. Isto porque o tipo de discurso histórico que visa o grande público ou a massa discente se caracteriza precisamente pela ausência de provas e de argumentos, sendo estes substituídos por afirmações dogmáticas ou por formas retóricas de persuasão. Não pretendo com isto dizer que não se observem também na produção historiográfica especializada marcas de dogmatismo ou de retórica, mas na verdade elas são menos visíveis do que nos textos históricos que visam o grande público ou nos manuais didáticos. Estas últimas formas de escritura merecem sem dúvida alguma uma análise detalhada, mas não é nelas que estou pensando ao abordar o tema desta mesa redonda.

Creio que podemos distinguir, na escritura histórica atual, vários lipos de enunciados que se alternam tecendo toda a compplicada trama do discurso histórico, quer se trate ainda de uma forma ligada à antiga história narrativa quer se trate de uma história predominantemente analítica.

Ressaltemos em primeiro lugar os enunciados retóricos, ou seja, aqueles que em geral abrem e fecham o discurso histórico, que estabelecem as ligações entre os vários capítulos, que forçam a adesão por meio de hábeis "logo", "portanto", "por consequiência", quando não ocorreu de modo algum a apresentação de um argumento explícito.

Em segundo lugar temos os enunciados descritivos da prática cientifica, cada vez mais abundantes na produção histórica atual, principalmente nos domínios da demografia histórica e da história social, nomeadamente na França. Este tipo de enunciados incide sobre:

a) delimitação do domínio de pesquisa, quer no que se refere ao nível de análise escolhido (econômico, social, demográfico, político, cultural), quer em relação às coordenadas de espaço e de temppo.

b) descrição das fontes utilizadas. Convém salientar a este respeito que a atual descrição das fontes pouco tem que ver com a chamada crítica externa ou interna, cujas regras encontramos explicitadas sobretudo em autores dos fins do século passado e inícios deste, comumente denominados "positivistas": Langlois e Seignobos. Hoje a descrição das fontes remete sobretudo para uma classificação dentro de uma tipologia documental (por exemplo, requerimento, lista nominativa de habitantes, registro paroquial de nascimento, casamento ou óbito, mapas de exportação e importação, listas eleitorais, relatórios, 
memórias, etc.) e também para uma apresentação das unidades de informação contidas nessas fontes, mesmo que o historiador só pretenda trabalhar com algumas dessas unidades informativas e não com todas. E que de certo modo hoje o historiador se preocuppa com o inventário das possibilidades informativas de qualquer fonte, antes de optar por aquelas que servem ao domínio de pesquisa recortado. E preciso lembrar ainda que o historiador recorre, embora com menos frequiência, a documentos não escritos, a fontes iconográficas, auditivas ou materiais, utilizadas como documentação básica (como no caso da documentação iconográfica no livro de Philippe Ariès sobre o lugar da criança na estrutura familiar do Antigo Regime), ou simplesmente como documentação complementar. Estes enunciados descritivos das fontes utilizadas aumentam em relação aos demais tipos de enunciados contidos no discurso histórico quando se trata de um trabalho de história quantitativa e mais ainda quando o historiador trabalhou com computadores. E que, como mostra Edward Shorter em The Historian and the Computer (1971), neste caso o historiador precisa de elaborar um código (codebook) que lhe permita passar a informação colhida na fonte para os cartões perfurados. Um dos exemplos apresentados por Shorter foi adaptado de um estudo sobre os 12.000 dossiers de prisão em Paris, no mês de junho de 1848, feito por A. Kriegel, R. Gossez e J. Rougerie, "Sources et méthodes pour une histoire sociale de la classe ouvrière", publicado em Le Mouvement social, n. 40 de 1962 . Os outros dois exemplos de códigos dizem respeito a recenseamentos americanos e ingleses.

c) descrição do tratamento dado às informações contidas nas fontes, depois da sua seleção. Estes enunciados ocupam igualmente um lugar importante quando se trata de um caso de história quantitativa, pois neste caso há que descrever os métodos estatísticos empregados, ou, quando se trata de uma história quantitativa mais sofisticada como a "New American History", um modelo matemático construído.

Em terceiro lugar podemos distinguir na escritura histórica aquilo que denominaremos os enunciados repetitivos, ou baseados em autoridades científicas. Vejamos um pouco mais de perto este tipo de enunciados. Muito embora não se possa falar da prática historiográfica como apresentando características cumulativas, ou por outras palavras, embora a produção de cada historiador não seja o fruto de uma acumulação do saber histórico, cristalizado nas obras dos que o precederam, devemos reconhecer que, em qualquer forma de escritura histórica atual, é possível detectar enunciados que repetem simplesmente as conclusões de outros historiadores, sem que esta incorporação ou assimilação exija do autor o ônus de qualquer prova ou argumento, que cabe apenas ao responsável por essas conclusões 
assim aceites e incorporadas. David Hackett Fischer, no seu livro Historians' Fallacies. Toward a Logic of Historical Thought, mostra o perigo destes enunciados repetitivos, ou de autoridade, e realmente há que pensar um pouco na questão de saber se um historiador que incorpora uma conclusão alheia não deverá repetir as provas e a argumentação apresentadas pelo seu colega, ou, caso elas não existam, tentar reconstituí-las, uma vez que ele é responsável não pelo enunciado original, mas pela sua aceitação e utilização.

Em quarto lugar, podemos distinguir os enunciados fatuais originais, ou enunciados descritivos. Neste caso, cabe ao historiador sem dúvida alguma o ônus da prova, mas, como observa Hackett Fischer, na obra há pouco citada, "não se observam comumente nem existe concordância geral acerca de modelos específicos de prova histórica" Ele próprio se limita a enunciar algumas regras simples, deduzidas da análise de uma série de falácias referentes à verificação fatual, por ele apontadas na obra de vários historiadores. Mas neste ponto específico, creio que maior ajuda podemos retirar do livro de Stephen Toulmin, The Uses of Argument (Cambridge, 1969), sobretudo no capítulo intitulado "The Layout of Arguments"

Toulmin esclarece uma série de pontos que geralmente o historiador confunde. Em primeiro lugar estabelece uma distinção importante entre a conclusão (C) que pretendemos estabelecer (em inglês ele usa claim ou conclusion) e os fatos para que apelamos como fundamento dessa conclusão e que ele denomina dados (D), em inglês data. Mas, acentua ele, há um passo (step) a ser dado quando apresentamos determinados dados como base para uma conclusão específica. O que nos permite dar tal passo, não é o recurso a mais dados, mas sim proposições de um tipo bastante diferente: regras, princípios, enunciados gerais que atuam como pontes entre os dados e a conclusão e que Toulmin denomina justificativa (warrant). Esta distinção entre dados e justificativas é importante para a análise da escritura histórica. Como diz Toulmin a justificativa aparece, em certo sentido, como incidental, sendo a sua função simplesmente registrar a legitimidade do passo dado. E é realmente preciso distinguir entre dados $\mathrm{e}$ justificativas porque o apelo aos dados é explícito sempre, ao passo que as justificativas estão implícitas e além disso são gerais.

Estas justificativas são de diferente espécie e podem conferir diferentes graus de força às conclusões que justificam. E preciso portanto acompanhar a conclusão de um qualificador modal (M) (representado pelos advérbios necessariamente ou provavelmente ou presuntivamente), assim como das condições de exceção.

Toulmin avança ainda mais na análise dos argumentos. Além da questão de saber se, ou em que condições, uma justificativa se 
aplica a um caso particular, há ainda a questão de saber por que razão em geral esta justificativa deve ser aceite como tendo autoridade. Chegamos assim à questão mais geral: se a justificativa é realmente aceitável. Ela por sua vez tem que se apoiar em alguma outra coisa que Toulmin chama de respaldo (backing) das justificativas. Ora, diz ele, estes respaldos variam de um campo de argumentação para outro. $\mathrm{Na}$ escritura histórica, este respaldo pode muito bem ser encontrado numa outra documentação diferente daquela que permitiu chegar a uma conclusão a partir de determinados dados.

Vemos assim que os enunciados fatuais originais exigem do historiador o ônus da prova e que cada momento dessa prova tem de ser claramente explicitado, mesmo no que se refere às justificativas, que, como diz Toulmin, estão geralmente implícitas, pois estas por sua vez exigem um respaldo.

Há finalmente a distinguir na escritura histórica um quinto tipo de enunciados, as hipóteses explicativas. O espaço ocupado no discurso histórico por estas hipóteses explicativas é menor do que habitualmente se supõe. Se analisarmos cuidadosamente uma produção historiográfica qualquer, observaremos que, não só as hipóteses explicativas se localizam em vários momentos do texto, sem jamais se concentrarem num só ponto, mas também elas são numericamente inferiores aos demais tipos de enunciados que compõem a trama da escritura histórica. Em geral as hipóteses explicativas só aparecem quando surge uma anomalia, um problema bem específico e neste caso o que se observa é que o historiador, depois de imaginar todo um leque de hipóteses e de as explicitar, tem de optar por uma e em relação a esta decisão é que se desenvolve o maior esforço argumentativo, pois o historiador tem de mostrar que esta hipótese é a mais provável em relação a todas as outras hipóteses alternativas.

Universidade de S. Paulo 